\title{
Indications for Anticoagulation in Cardiac Amyloidosis
}

\author{
Marcelo Westerlund Montera ${ }^{\circledR}$ \\ Hospital Pró Cardíaco, Centro de Insuficiência Cardíaca, Rio de Janeiro, RJ - Brazil
}

In cardiac amyloidosis, amyloid infiltrate at the atrial level promotes atrial dilation and contractile dysfunction as well as a higher prevalence of atrial fibrillation which, when associated with ventricular diastolic and systolic dysfunction, favors blood stasis and the consequent development of intracardiac thrombosis (ICT) and cardioembolic events.

In a study of 116 autopsies of patients with cardiac amyloidosis, conducted at the Mayo Clinic, the presence of ICT was demonstrated in $33 \%$ of hearts, with a significantly higher prevalence in patients with the $\mathrm{AL}$ form of amyloidosis than in those with other forms (56\% versus $16 \%, p<0.001){ }^{1}$

When evaluating 324 patients with cardiac amyloidosis using cardiac magnetic resonance, we found an ICT prevalence of $6.2 \%$, with $90 \%$ located in the atrial appendage. Among the patients, $70 \%$ had atrial fibrillation, and $30 \%$ had sinus rhythm, with a similar prevalence of ICT in the AL (5.2\%) and ATTR forms (7.2\%). ${ }^{2,3}$

Morphological and functional changes caused by atrial amyloid infiltrate favor the development of atrial fibrillation, with a prevalence ranging from $29 \%$ to $60 \%$, depending on the population, and it is more prevalent in the ATTR form, given that it affects an older population. The presence of atrial fibrillation poses a high risk for the development of ICT and stroke, especially in patients with AL amyloidosis. ${ }^{4}$

Approximately $20 \%$ to $30 \%$ of patients who have ICT, as well as $27 \%$ of patients with cerebral ischemic events are in sinus rhythm. ${ }^{3,5}$

The probable mechanism responsible for the development of thrombotic events and thromboembolism in patients in sinus rhythm would be the presence of atrial myopathy due to amyloid infiltrate and high ventricular filling pressures, which induce atrial contractile dysfunction and favor blood stasis and ICT formation. ${ }^{5-7}$

By means of logistic regression analysis, several factors have been identified that are related to greater predisposition to ICT and thromboembolic

\section{Keywords}

Cardiac Amyloidosis; Intracardiac Thrombosis: Anticoagulation; Stroke Prevention.

Mailing Address: Marcelo Montera •

Rua Redentor, 111/301. Postal Code: 22421030, Ipanema, Rio de Janeiro, RJ - Brazil.

E-mail: mmontera@uol.com.br

Manuscript received October 04, 2021, revised manuscript October 15 2021, accepted October 15, 2021.

DOI: https://doi.org/10.36660/abchf.20210032 events, such as biventricular systolic dysfunction, restrictive pattern of diastolic dysfunction, atrial dilatation, degree of atrial amyloid infiltration, and high NT-proBNP levels. In the presence of these factors, we must carry out a specific evaluation as to the possible benefit of anticoagulation for preventing cardioembolic events. $^{2}$

In patients with cardiac amyloidosis who have ICT or atrial fibrillation, anticoagulation treatment is absolutely indicated, due to the benefits in reducing thromboembolic events and improving survival. ${ }^{8}$

New anticoagulants and coumarin are similar in terms of benefits in reducing stroke and increasing survival, as well as in terms of increasing the incidence of bleeding events. Approximately $55 \%$ to $68 \%$ of patients taking coumarin have difficulties reaching the stable therapeutic target of the international normalized ratio, especially in the elderly population, which we must take into account when making decisions regarding the choice of new anticoagulants as an alternative for anticoagulation. ${ }^{9-11}$

Even though anticoagulation in patients with amyloidosis has been associated with an increased risk of bleeding events due to amyloid angiopathy, especially in patients with the ATTR form, who are at risk of intracranial hemorrhage, this risk does not outweigh the benefits of preventing thromboembolic events; therefore, anticoagulation should be carried out when it is indicated. ${ }^{12-13}$

\section{Author Contributions}

Writing of the manuscript and Critical revision of the manuscript for intellectual content: Montera MW.

\section{Potential Conflict of Interest}

No potential conflict of interest relevant to this article was reported.

\section{Sources of Funding}

There were no external funding sources for this study.

\section{Study Association}

This study is not associated with any thesis or dissertation work.

\section{Ethics approval and consent to participate}

This article does not contain any studies with human participants or animals performed by any of the authors. 


\section{References}

1. Cannistraro RJ, Meschia JF. The Clinical Dilemma of Anticoagulation Use in Patients with Cerebral Amyloid Angiopathy and Atrial Fibrillation. Curr Cardiol Rep. 2018;20(11):106. doi: 10.1007/s11886-018-1052-1.

2. Martinez-Naharro A, Gonzalez-Lopez E, Corovic A, Mirelis JG, Baksi AJ, Moon JC, et al. High Prevalence of Intracardiac Thrombi in Cardiac Amyloidosis. J Am Coll Cardiol. 2019;73(13):1733-4. doi: 10.1016/j. jacc.2019.01.035

3. Feng D, Edwards WD, Oh JK, Chandrasekaran K, Grogan M, Martinez MW, et al. Intracardiac Thrombosis and Embolism in Patients with Cardiac Amyloidosis. Circulation. 2007;116(21):2420-6. doi: 10.1161/ CIRCULATIONAHA.107.6977636.

4. Zubkov AY, Rabinstein AA, Dispenzieri A, Wijdicks EF. Primary Systemic Amyloidosis with Ischemic Stroke as a Presenting Complication. Neurology. 2007;69(11):1136-41. doi: 10.1212/01.wnl.0000276951.39112.2b.

5. Cappelli F, Tini G, Russo D, Emdin M, Del Franco A, Vergaro G, et al. Arterial Thrombo-Embolic Events in Cardiac Amyloidosis: A Look Beyond Atrial Fibrillation. Amyloid. 2021;28(1):12-8. doi: 10.1080/13506129.2020.1798922.

6. Dubrey S, Pollak A, Skinner M, Falk RH. Atrial Thrombi Occurring During Sinus Rhythm in Cardiac Amyloidosis: Evidence for Atrial Electromechanical Dissociation. Br Heart J. 1995;74(5):541-4. doi: 10.1136/hrt.74.5.541.

7. Roudaut R, Pepin C, Marazanof M, Bonnet J. Systemic embolism and thrombosis of the left atrium in a patient in sinus rhythm with cardiac amyloidosis. Ann Cardiol Angeiol. 1996;45(3):119-21.

8. Feng D, Syed IS, Martinez M, Oh JK, Jaffe AS, Grogan M, et al. Intracardiac Thrombosis and Anticoagulation Therapy in Cardiac
Amyloidosis. Circulation. 2009;119(18):2490-7. doi: 10.1161/ CIRCULATIONAHA.108.785014.

9. Mitrani LR, Santos J, Driggin E, Kogan R, Helmke S, Goldsmith J, et al. Anticoagulation with Warfarin Compared to Novel Oral Anticoagulants for Atrial Fibrillation in Adults with Transthyretin Cardiac Amyloidosis: Comparison of Thromboembolic Events and Major Bleeding. Amyloid. 2021;28(1):30-4. doi: 10.1080/13506129.2020.1810010.

10. Rohla M, Weiss TW, Pecen L, Patti G, Siller-Matula JM, Schnabel RB, et al Risk Factors for Thromboembolic and Bleeding Events in Anticoagulated Patients with Atrial Fibrillation: The Prospective, Multicentre Observational Prevention of Thromboembolic Events - European Registry in Atrial Fibrillation (PREFER in AF). BMJ Open. 2019;9(3):e022478. doi: 10.1136/ bmjopen-2018-022478.

11. Agarwal S, Hachamovitch R, Menon V. Current Trial-Associated Outcomes with Warfarin in Prevention of Stroke in Patients with Nonvalvular Atrial Fibrillation: A Meta-Analysis. Arch Intern Med. 2012;172(8):623-31. doi: 10.1001/archinternmed.2012.121.

12. Adam SS, McDuffie JR, Ortel TL, Williams JW Jr. Comparative Effectiveness of Warfarin and New Oral Anticoagulants for the Management of Atrial Fibrillation and Venous Thromboembolism: A Systematic Review. Ann Intern Med. 2012;157(11):796-807. doi: 10.7326/0003-4819-157-10201211200-00532.

13. Ntaios G, Papavasileiou V, Diener HC, Makaritsis K, Michel P. NonvitaminK-Antagonist Oral Anticoagulants in Patients with Atrial Fibrillation and Previous Stroke or Transient Ischemic Attack: A Systematic Review and MetaAnalysis of Randomized Controlled Trials. Stroke. 2012;43(12):3298-304. doi: 10.1161/STROKEAHA.112.673558. 